\title{
An Analysis of Behavioral Intention toward Actual Usage of Open Source Software among Students in Private High Learning Institution in Tanzania
}

\author{
Alberto Gabriel Ndekwa ${ }^{1}$, Edephonce Ngemera Nfuka ${ }^{2}$, Kalugendo Elizeus John ${ }^{3}$ \\ ${ }^{1}$ Postgraduate Student, The Open University of Tanzania \\ ${ }^{2}$ Lecturer-The Open University of Tanzania \\ ${ }^{3}$ Postgraduate Student-The Open University of Tanzania
}

\begin{abstract}
This study focused on analyzing behavioral intention toward the actual usage of open source software in private universities in Tanzania. Questionnaires were used to collect quantitative data in two private universities namely Iringa University and Ruaha Catholic University. Stratified sampling technique was utilized to ensure sample representativeness among two universities where simple random sampling was used to draw a sample from each stratum during the survey.

Finding Using Structural Equation Modeling indicated that performance expectancy (source code production and software localization) and social factor (Vendor, internet services provider and lecturer) have a significant influence toward behavioral intention while effort expectancy was found to be insignificant. In addition the behavioral intention was found to be significant toward student's actual usage of open source software in Universities. This study recommended that for students to develop behavioral intention toward OSS actual usage, internet service provider have to increase the level of internet services that can assist the university communities to access and download open source software. In addition, to increase actual use, open source software vendors and lecturer or experts have to make sure that their software source code is free for distribution and localization, this will increase selfmotivation and interest of the students toward actual usage of open source software.
\end{abstract}

Keyword-Behavior Intention, Open Source Software, Actual Usage, Private University.

\section{INTRODUCTION}

It is well evidenced that the adoption of open source software has been regarded as a strategy for enhancement of
Information Technology usage in an education setting. Dehinbo and Dehinbo (2013) advocated, that the recent changes in the software technologies landscape involve the introduction of OSS which presents certain benefits and freedom in the use of software that demonstrates high potential towards achieving competitive advantage by institutions of higher learning. As argued by Kibe (2014) that the adoption and use of open source software(OSS), especially in institutions of higher learning can play a fundamental responsibility in the formation of new knowledge, distribution and ultimate application of OSS in the economy and society as a whole. Hence higher institutions of learning stand to gain the benefits of teaching, learning and research in particular by adopting OSS.

Despite its benefit, it is well evidenced that African government and private institution have also not taken the lead in adopting the OSS software and many do not have policies in places regarding it (Kamau and Namuye, 2012).This is supported by a recent report on OSS market share product which revealed, that OSS products such as Linux and Firefox are lagging considerably behind in adoption (Shaame,et al.,2013). As argued by Kamua and Sanders (2013) usability is also important attribute in software and has been defined as the extent to which a product can be used by specified users to achieve specified goals with effectiveness, efficiency and satisfaction in a specified context of use.Despite the low uptake, very few studies have been done to analyze the influence of behavioral intention toward actual usage. Even those few studies each has come with unique finding. Shaame, et al.(2013) found that the reasons for adopting OSS are vary from one country to another and from one institution to 
another. Given this situation this study filled the gap by analyzing behavioral intention toward actual usage of OSS in Tanzania private higher learning institutions.

\section{THEORETICAL LITERATURE REVIEW AND CONCEPTUAL FRAMEWORK}

\subsection{Theoretical Literature Review}

Although several studies applied Unified Theory of Acceptance and Use of Technology (UTAUT) in various organizational and cultural contexts, very few implemented the full model and examined all of its constructs of behavioral intention toward actual usage in a higher education setting. This study places itself in the area where there are very few exhaustive studies by focusing on students in higher education and open source software technology that is new to them, and using the full UTAUT model without moderators and facilitating condition. Also, this research addresses the question of whether UTAUT is applicable in an academic environment in which educational technologies are introduced to the students.
According to Venkatesh, et al. (2003) the behavioral intention to actual use is determined by Performance expectancy, Effort expectancy and Social influence where Facilitating conditions have direct influence on actual use behavior as indicated in Figure 1 and associated items definition below. Schaik (2009) in his study of unified theory of acceptance and use by students in higher education, his results demonstrated the broad scope of applicability of UTAUT and motivate wider use.

Performance expectancy: Is the degree to which an individual believes that using the system will help him or her to attain gains in job performance.

Effort expectancy: is the degree of easiness associated with the use of the system.

Facilitating conditions: is the degree to which an individual believes that an organizational and technical infrastructure exists to support use of the system.

Social influence: is the degree to which an individual perceives that it is important others to believe he or she should use the new system.

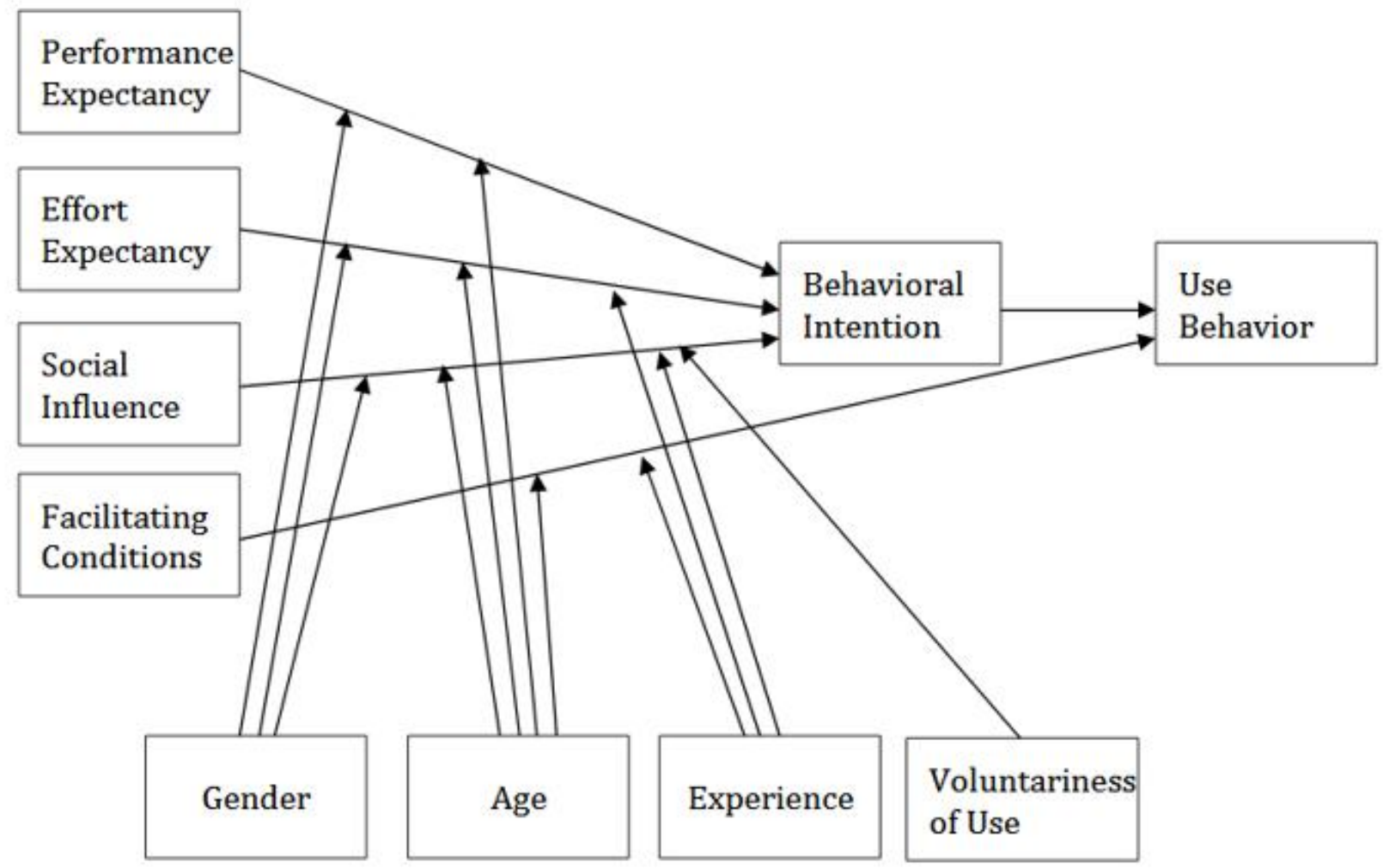

Fig.1: The Unified Theory of Acceptance and Use of Technology (UTAUT)

The applicability of using UTAUT Model in adoption studies have been found in a number of empirical evidence. For example Decman (2015) found and proved the general applicability of the UTAUT model in e-learning settings and demonstrated that Social influence and Performance expectancy significantly influence the Intention to use elearning in mandatory environments of higher education. Chumo and Kessio (2015) applied UTAUT model to assess ICT adoption in Kenyan Universities, the results found and concluded that Effort expectancy, performance expectancy 
and Social influence factors affect the student's behavioral intention and ultimately affects actual usage. Shaame, et al. (2013) on their study of drivers to adoption of FOSS in higher education, found total cost ownership, free to make copies and distribute to others without being worried of software legality, reliability, availability, performance and security issues were the drivers for adoption. Kibe (2014) found that awareness through training is one of the significant determinants of OSS adoption. He further found that cheaper, easy to install, easily upgradable, more reliable and more secure have an impact on behavioral intention.
Consistent with UTAUT, and empirical evidence above, this research theorizes the following:

H1: Performance expectancy has a positive and significant influence on behavioral intention toward OSS

H2: Effort expectancy has a positive and significant influence on behavioral intention toward OSS

H3: Social influence has a positive and significant influence on behavioral intention toward OSS

H4: Behavioral intention has a positive and significant influence toward OSS actual usage

2.2 Conceptual Framework

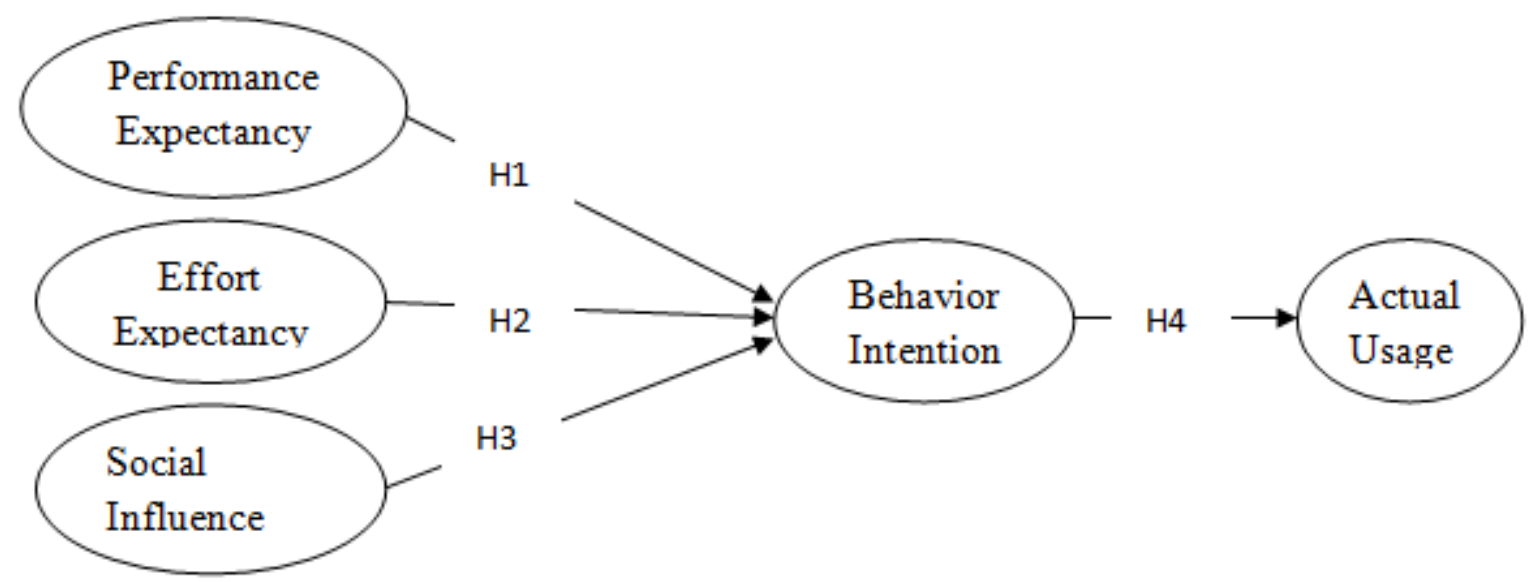

Fig.2: Conceptual Framework

\section{METHODOLOGY}

The objective of this study was to examine the influence of the factors of UTAUT on open source software adoption by the students in a private higher education institution in Tanzania. Hypothesis developed form UTAUT was tested by using Structural Equation Modeling analysis in a data collected from students in two private institutions namely Iringa University and Ruaha Catholic University. Stratified sampling technique was used to ensure fair representation of sample from these two universities then simple random was used to draw a sample. Questionnaire was used to collect data from the field while documentary review was used to provide evidence and support findings from the field.

\section{MAJOR FINDINGS}

\subsection{Confirmatory Factor Analysis}

At the beginning, the researcher developed a conceptual framework, at this stage he wanted to confirm and harmonize a belief about how the original variables are organized in a required way using Confirmatory Factor
Analysis (CFA). CFA was used to analyze theoretical constructs through assessing the loading of the measures, error variances and covariance (Hooper, et al., 2008).

In order to reach a measurement model that fits both components, CFA wasrun with maximum likelihood estimate in IBM Amos 20 to determine its fitness. After initial run, the results showed a bad model fit with $\mathrm{CMIN} / \mathrm{DF}=8.263, \mathrm{GFI}=0.711, \mathrm{AGFI}=0.662, \mathrm{CFI}=0.702$ and $\mathrm{RMSEA}=0.109$. Based on Hoe (2008) recommendation which requires a model to achieve the following minimum requirements CFI ( $>0.90$ indicates good fit), RMSEA $(<0.08$ indicates acceptable fit), and commonly used $\chi 2$ statistic ( $\chi 2 /$ df ratio of 3 or less) to be considered fit.

To improve the model, some items that were affecting the significance of the model's fitness were removed as recommended by Hooper, et al. (2008).

At this point, elimination was made at item level and items that were removed not only were weakening the model but were also indicating weak statistical power.

After removing those items in the model, re-running the model indicated adequate fit results with $\mathrm{CMIN} / \mathrm{DF}=3.160$, 
GFI=0.966, $\quad$ AGFI=0.949, $\quad$ CFI=0.995 and RMSEA $=0.028$. On the other hand, the observed variables with significant probabilities have positive standardized regression weights greater than 0.50 and standardized path coefficients between measured variables and factors in the models show that all path coefficients between measured (manifest) variables and latent (un-observed)variables in the model are significant $(\mathrm{p}<0.05)$. These results indicate that most of the factor loadings explaining the measurement model are adequate and thus reflects avery good reliability of the research constructs. As recommended by Hox and Bechger (2014) factors loading lower than 0.5 are not significant while Bentler and Yuan (2000) indicated that a negative regression weight on the other hand presents doubtful measurement models. In our case, the researcher has achieved the above good results; hence a robust measurement model was achieved as illustrated in Figure 3 below. The retained items were used in the final analysis of the structural model.

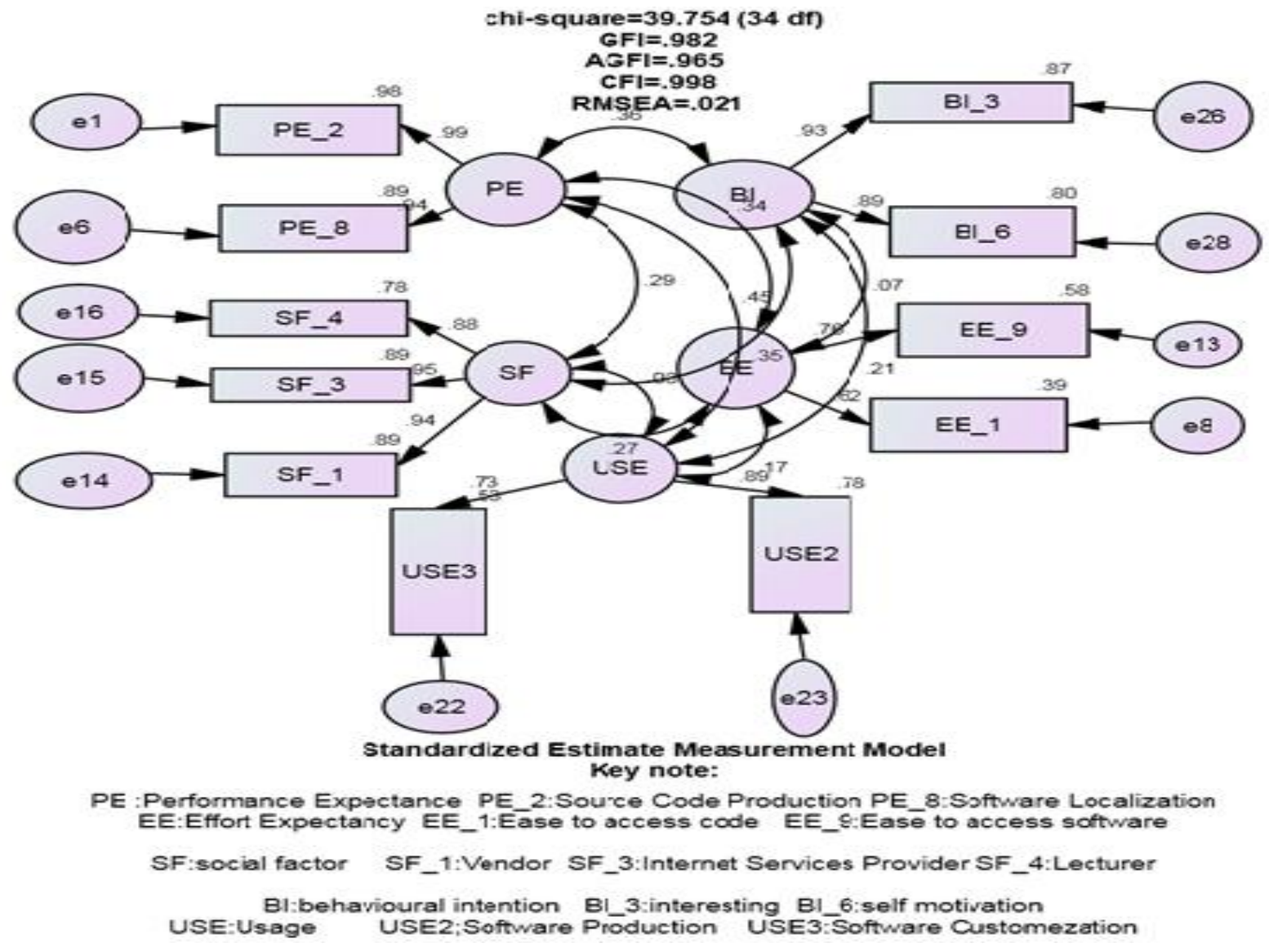

Fig.3: Measurement Model

The retained items were used in the final analysis in the structural model as described in the next section.

\subsection{Structural Model}

The basic structural model of the study which hypothesized the relationship between Performance expectancy, Effort expectance and Social influence on FOSS adoption was analyzed. The results of the analysis using AMOS version 20 are diagrammed Figure 4 below and the results for the goodness of fit indices based on four indices namely CMIN/DF,CFI,AGFI and RMSEA are presented in Figure 4. 


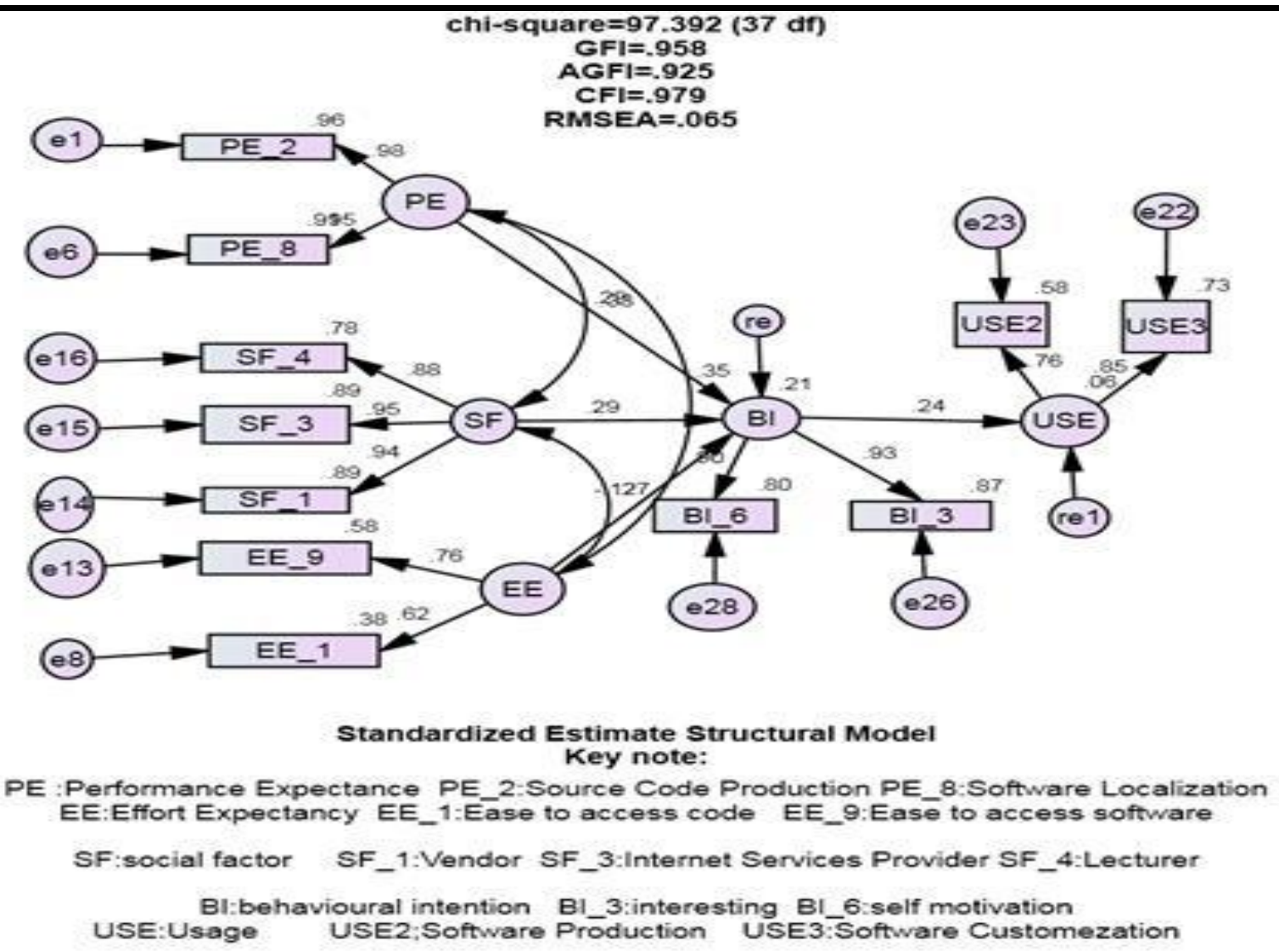

Fig.4: Structural Model

The findings for model fit in Figure 4 are elaborated as follows: The ratio of the $\chi 2$, to the degree of freedomCMIN/DF commonly referred to as normed chi-square value has yielded a value of 1.304 , which has range to the suggested cut of point values $<2$ or $<3$ by (Clemons, $\&$ Row, 1991). The CFI $=0.995$, GFI $=0.966$ and AGFI $=0.949$ obtained fall under the acceptable range whereas values close to 1 and generally values above 0.9 indicate a good fit as suggested by Clemons, \& Row(1991). On the other hand, as suggested by Hoe (2008) that a RMSEA value of $0=$ indicate perfect fit, $<0.05=$ indicate close fit, 0.05 to 0.08 indicate fair fit and 0.08 to 0.1 a mediocre fit, $>0.1=$ poor fit. Comparing to the current study findings the RMSEA values of 0.028 which was produced in the analysis indicate that the model fits very well with the data. Having established a model fit which indicates a good fit using four indices, the path coefficient and hypothesis testing were evaluated as explained in the next section using this model.

\subsection{Path Coefficient and Hypothesis Testing}

The structural model was used to test the hypothesized relationships. The hypothesized relationships are examined against various coefficients and scores obtained from the analysis. A standardized paths coefficient, critical value(C.R) and significant level(p) were used in this study in the testing and evaluation of strength and the level of significance of the hypotheses. The four hypotheses which were developed their results are presented as follows.

H1: Performance expectancy has a positive and significant influence on behavioral intention toward OSS

To test this hypothesis, structural equation modeling was used and the results are indicated in Table 1

Table.1: The Influence of Performance Expectancy on Behavioral Intention

\begin{tabular}{|c|c|c|c|c|c|c|c|c|}
\hline \multicolumn{3}{|c|}{ Path } & Estimate & S.E. & C.R. & & S.R.W & Remarks \\
\hline BI & $<--$ & $\mathrm{PE}$ & .336 & .058 & 5.773 & $* * *$ & 0.329 & Accepted \\
\hline PE_8 & $<--$ & PE & 1.035 & .044 & 23.700 & $* * *$ & 0.953 & Accepted \\
\hline PE_2 & $<--$ & PE & 1.000 & & & & 0.980 & Accepted \\
\hline
\end{tabular}


The path leading from $P E$ to $B I$ in table 1 is used to examine the relationship between performancy expectance and university student's behavior intention. A positive path coefficient $(\gamma=.329)$ using standardized estimate, critical values $(C . R=5.773$ which is $>1.96)$ and a significance level of $p=0.000 \mathrm{in}$ Table 1 above indicates that performance expectancy is positively and significantly related to university students behavior intention. This concurs with Chin (1998)and Hoe (2008) who argued that standardized path coefficient $(\gamma)$ should be at least 0.2 , critical ration greater than 1.96 and a p-value less than 0.05 to be considered significant.

H2: Effort expectancy has a positive and significant influence on behavioral intention toward OSS

The influence of effort expectance on behavioral intention is tested using structural equation modeling as described in Table 2.

Table.2: The Influence of Effort Expectant on Behavioral Intention

\begin{tabular}{|c|c|c|c|c|c|c|c|c|}
\hline \multicolumn{3}{|c|}{ path } & Estimate & S.E. & C.R. & & S.R.W & Remarks \\
\hline BI & $<---$ & $\mathrm{EE}$ & -.135 & .078 & -1.722 & .085 & -0.119 & Rejected \\
\hline EE_9 & $<---$ & $\mathrm{EE}$ & 1.000 & & & & 0761 & Accepted \\
\hline EE_1 & $<---$ & $\mathrm{EE}$ & .907 & .177 & 5.124 & $* * *$ & 0.620 & Accepted \\
\hline
\end{tabular}

The path leading from $E E$ to $B I$ in Table 2 is used to examine the relationship between effort expectance and Behavior intention. A positive path coefficient $(\gamma=-0.119)$ using standardized estimate, critical values $(C . R=-1.722$ which is <1.96) and significance level of $p=0.000$ in Table 2 above indicates that effort expectancies negative and insignificant related to Behavior intention. This concurs with Chin (1998) and Hoe (2008) who argued that a standardized paths coefficient $(\gamma)$ should be at least 0.2 , critical ration greater than 1.96 and $\mathrm{p}$-value less than 0.05 to be considered significant.

H3: Social influence has a positive and significant influence on behavioral intention toward OSS

To test this hypothesis, structural equation modeling was used, and the results are demonstrated in Table 1

Table.3: The Influence of Social Factor on Behavioral Intention

\begin{tabular}{|c|c|c|c|c|}
\hline & Estimate & $\begin{array}{ll}\text { S.E. } & \text { C.R. }\end{array}$ & S.R.W & Remarks \\
\hline BI <--- SF & .251 & 5.244 & $* * * 0.289$ & Accepted \\
\hline SF_3 <--- SF & 1.030 & $.035 \quad 29.120$ & $* * * 0.883$ & Accepted \\
\hline SF_4 <--- SF & 1.000 & & 0.946 & Accepted \\
\hline $\mathrm{SF}_{-} 1<--\mathrm{SF}$ & 1.032 & .03628 .961 & $* * * 0.943$ & Accepted \\
\hline
\end{tabular}

The path leading from $S F$ to $B I$ in Table 3 is used to examine the relationship between Social factor and Behavior intention. A positive path coefficient $(\gamma=.289)$ using standardized estimate, critical values $(\mathrm{C} . \mathrm{R}=5.244$ which is >1.96) and significance level of $p=0.000$ in Table 3 above indicates that Social influences positively and significant related to university students Behavior intention.
This concurs with Chin (1998)and Hoe (2008) who argued that a standardized paths coefficient $(\gamma)$ should be at least 0.2 , critical ration greater than 1.96 and p-value less than 0.05 to be considered significant.

H4: Behavioral Intention has a positive and significant influence toward OSS actual usage

Table.4: The Influence of Behavior Intention on Actual Usage

\begin{tabular}{|lll|rrrcc|l|}
\hline Path & & & Estimate & S.E. & C.R. & P & S.R.W & Remarks \\
\hline USE & $<---$ & BI & .165 & .049 & 3.383 & $* * *$ & 0.237 & Accepted \\
BI_3 & $<---$ & BI & 1.000 & & & & 0.930 & Accepted \\
BI_6 & $<---$ & BI & 1.057 & .071 & 14.812 & $* * *$ & 0.895 & Accepted \\
\hline
\end{tabular}

The path leading from $B I$ to $U S E$ in Table 4 is used to examine the relationship between behavior intention and Actual Usage. A positive path coefficient $(\gamma=.237)$ using standardized estimate, critical values $(C . R=3.383$ which is $<1.96$ ) and a significance level of $p=0.000$ in Table 4 above indicates that behavior intentions positively and significant 
related to actual usage of OSS among students. This concurs with Chin (1998) and Hoe (2008) who argued that a standardized path coefficient $(\gamma)$ should be at least 0.2 , critical ration greater than 1.96 and p-value less than 0.05 to be considered significant.

\section{CONCLUSION}

This paper mainly focuses on the behavioral intention of the university students toward usage of OSS within the University. Considering that university students are crucial for the effective use of the OSS in higher education, it is important to understand their behavioral intentions to the system and the factors that influence these intentions. This study has found and concluded that performance expectancy and social influence has a significant influence on behavioral intention. In addition, this study has found and concludes that Behavioral intention has a positive and significant influence towards FOSS actual usage. We found and concluded that effort expectancy doesn't play a crucial role in the behavioral intention to actual usage. This finding implies that: while software localization was found to have an impact, this study recommends that to improve actual usage vendors or lecturer or experts have to develop OSS which are localized in the context of university students.

While the internet was found to be significant, this study recommends that internet service provider have to ensure efficient and effective internet services that could enable access to OSS.

Self-motivation and interest in OSS were also observed to influence actual usage, this implies that students have to be motivated in accessing the source code for software source code production. These have to be done by lecturers and vendors.

\section{REFERENCES}

[1] Chin, W.W. (1998). Issues and Opinion on Structural Equation Modelling. MIS Quarterly, 22(1), Preceding .1(1), 1-10.

[2] Clemons, E.K, \& Row, M.C. (1991). Sustaining IT Advantage: The Role of Structural Differences. MIS quarterly, 15 (3), 275-292.

[3] Chumo, K.P.\& Kessio, J.(2015).Use of UTAUT Model to Asses ICT Adoption in Kenyan Public Universities. Information and Knowledge Management. 5(12), 79-84.

[4] Decman,M.(2015) Modeling the acceptance of elearning in mandatory environments of higher education: The influence of previous education and gender. Computers in Human Behavior.49. 272-281.
[5] Dehinbo,K.O. \& Dehinbo, J. O. (2013).Towards Suitable Research Paradigm for Assessing the Impact of Free and Open Source Software (FOSS) Proceedings of the World Congress on Engineering and Computer Science Vol I , 23-25 October, San Francisco, USA.

[6] Hoe, S. L.(2008).Issues and Procedures In Adopting Structural Equation Modeling Technique. Journal of Applied Quantitative Method. 3(8) 79-83.

[7] Hox, J.J \& Bechger,T.M.(2000).An Introduction to Structural Equation Modeling. Family Science Review.11(2), 354-373.

[8] Hooper, D., Coughlan, J. and Mullen, M. R.(2008).Structural Equation Modelling: Guidelines

[9] for Determining Model Fit. The Electronic Journal of Business Research Methods.6(2),66-77.

[10] Kamau, J.W.\& Sanders,I.D.(2013). An Empirical Investigation into the Effect of Usability on Adoption of Desktop Open Source Software by University Students in Kenya. Computer and Information Science. 6(3),108-117.

[11] Kibe, A. (2014).Training as a Determinantof Open Source -Software Applications Adoption in Universities.International Journal of Academic Research in Business and Social Sciences. 4 (8), 420429.

[12] Kamau,J. \&Namuye,S. (2012). A Review of Users Adoption of Open Source Software in Africa.Computer and Information Science. 5(5), 4555.

[13] Shaame,A., Shanmugam,K.\& Dehghantanha,A. (2013). An Educational Framework for Free and Open Source Software. International Journal of Innovation, Management and Technology. 4(1), 16-20.

[14] Schaik, P. (2009).Unified theory of acceptance and use for websites used by students in higher education. Journal of Educational Computing Research, 40 (2), 229-257.

[15] Shaame,A., Shanmugam, K. \& Dehghantanha, A.(2013). An Educational Framework for Free and Open Source Software. International Journal of Innovation, Management and Technology. 4(1),16-20.

[16] Venkatesh, V., Morris, M.G., Davis, F.D., \& Davis, G.B. (2003).User Acceptance of Information Technology: Toward a Unified View. MIS Quarterly, 27 